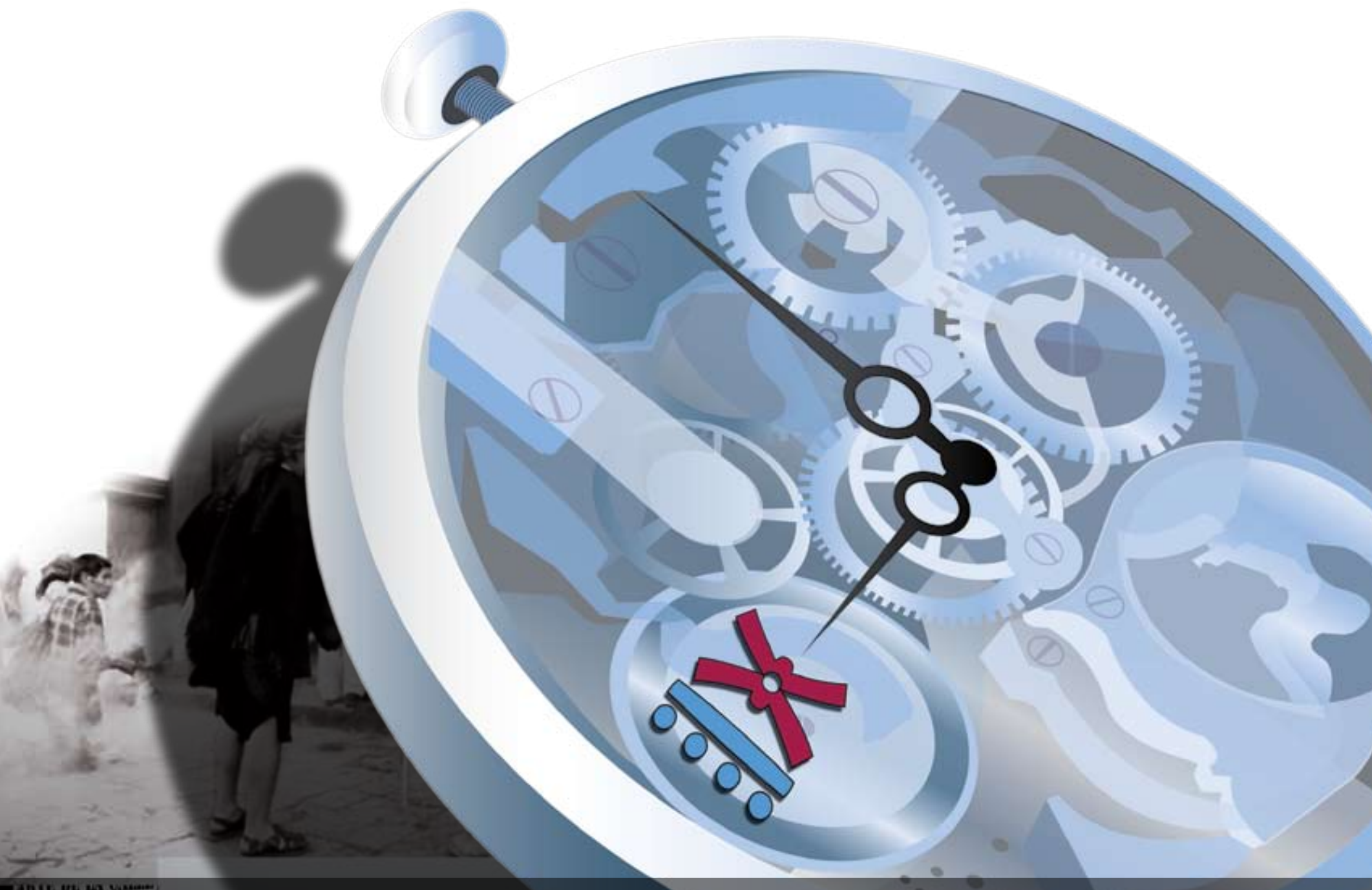

$9^{\circ}$ C O N G R E S O 2. CENTROAMERICANO DE H ISTO R I A

Universidad de Costa Rica ISSN 1409- 469X

Fecha de recepción: 15 de mayo 2008 Fecha de aceptación: 30 de mayo 2008

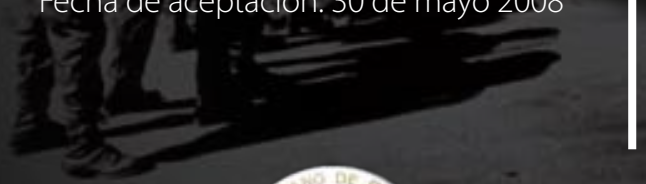

"La hora del sacrificio": el Partido Confraternidad Guanacasteca y su éxito fugaz

Miembros del Consejo Editorial:

Dr. Ronny Viales, Dr. Juan José Marín

Editores Técnicos:

Allan Fonseca, Andrés Cruz, Gabriela Soto
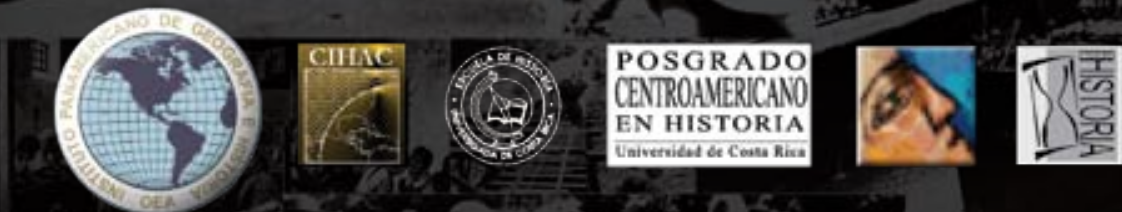
Indexaciones: Repositorio de Revistas UCR, DIALNET, Latindex, REDALYC Directorio y recolector de recursos digitales del Ministerio de Cultura de España, Directory of Open Access Journals. Diálogos Revista Electrónica de Historia ISSN 1409-469X. Número especial 2008. Dirección web: http://historia.fcs.ucr.ac.cr/dialogos.htm

\section{"La hora del sacrificio": el Partido Confraternidad Guanacasteca y su éxito fugaz}

Soili Busca

Apdo 787-2050

San Pedro, Montes de Oca

Costa Rica

506 - 22074648

soili.buska@ucr.ac.cr

Universidad de Costa Rica 


\section{Introducción}

La fundación del Partido Confraternidad Guanacasteca en 1937 fue el resultado de un proceso de tres décadas de elaboración del regionalismo guanacasteco en Costa Rica. Desde inicios del siglo veinte, la prensa costarricense comenzó a brindar espacio a columnistas que elaboraban un discurso sobre la identidad regional guanacasteca y promovían la unidad entre los guanacastecos. Hacia la década de 1930, se había generado un discurso heterogéneo pero con ciertos rasgos en común, que se refería a la provincia de Guanacaste como la cenicienta de la nación, como la comunidad injustamente abandonada por el estado nacional y el rincón que había sido expulsado del vagón del progreso. La coyuntura de la celebración del centenario de la anexión del Partido de Nicoya a Costa Rica y la conmemoración oficial del centenario en el mes de febrero de $1925^{1}$ hicieron que los intelectuales y activistas guanacastecos decidieran trabajar de una manera más sistemática un discurso regionalista, que demandaba obras del progreso y llamaba a los guanacastecos a organizarse y a luchar por sus derechos como miembros legítimos de la nación. Así, con base en estas construcciones discursivas, a mediados de la década del treinta, surgió una organización política que adquirió una fuerza considerable y un éxito importante en las elecciones nacionales. Sin embargo, el éxito inicial del Partido Confraternidad Guanacasteca no generó bases para una articulación sólida de las fuerzas regionalistas a más largo plazo, sino que, después de una euforia inicial, las posibilidades de este partido en la política nacional se extingieron rápidamente.

\section{Los primeros pasos en la organización hacia el partido político}

La organización regionalista guanacasteca emergió al mismo tiempo en que la paz social en Guanacaste estaba en severo peligro. Como consecuencia de la crisis económica mundial, las exportaciones costarricenses disminuyeron de 18 millones a 8 millones de dólares, entre 1929 y 1932. ${ }^{2}$ En respuesta, los hacendados guanacastecos impusieron con éxito niveles

$1 \quad$ Sobre las conmemoraciones del centenario de la anexión, ver Soili Buska, “Guanacaste: el surgimiento de un discurso regionalista, 1900-1926”, Revista de Historia (Universidad Nacional; Universidad de Costa Rica) 53-54 (2006), en prensa.

2

Iván Molina Jiménez y Steven Paul Palmer, Costa Rica, 1930-1996: historia de una sociedad (San José: Porvenir, 1997), 9. 
crecientes de explotación mediante los recortes de salarios y desmejoramiento de las condiciones de trabajo y, por tanto, la situación de las clases bajas comenzó a deteriorarse a mediados de los años 1930. Si a en la década de 1920 e inicios de 1930, los salarios en las haciendas guanacastecas habían sido más elevados que los que recibían los trabajadores cafetaleros del centro del país, hacía mediados de los años 30, los salarios de los peones de hacienda comenzaron a bajar rápidamente. ${ }^{3}$ En vez de escasez, ahora había abundancia de mano de obra en las haciendas, y en la medida en que los salarios bajaban y las condiciones de trabajo empeoraban, más y más guanacastecos buscaron trabajo fuera de la provincia. ${ }^{4}$ Como consecuencia de la crisis, adicionalmente a los conflictos de tierras entre pequeños campesinos y latifundistas, los trabajadores de hacienda comenzaron a luchar por mejores salarios y condiciones de trabajo.

Paralelamente al aumento en los niveles de explotación en la economía ganadera de Guanacaste a mediados de la década de 1930, un grupo de guanacastecos-principalmente, intelectuales y políticos de sectores medios-comenzaron a trabajar sistemáticamente para formar un movimiento político regionalista basado en una identidad regional. Se imaginaron Guanacaste como una región única y una comunidad unida con una cultura y una historia particulares y con intereses económicos y políticos comúnes para los habitantes de la provincia. En condiciones internas de conflictos sociales crecientes, la provincia se imaginaba como una región y una comunidad unida por intereses comúnes.

Unos años antes del surgimiento del partido político, en agosto 1934, un grupo de guanacastecos residentes en la ciudad capital fundaron la asociación La Casa de Guanacaste, con el propósito de “mejorar la vida cultural y material” en Guanacaste por medio de información y educación

3

Edelman, The Logic of the Latifundio, 113, 116.

4

Ibid., 117. Según Carlos Dávila, alrededor de 26.000 guanacastecos emigraron en los años 30. Carlos Dávila Cubero, ¡Viva Vargas! Historia del Partido Confraternidad Guanacasteca (San José, Costa Rica: Ediciones Guayacán, 1987), 33, 131. Las experiencias crueles de los emigrantes guanacastecos en la zona bananera de Pacífico sur son descritas en la novela regionalista de Ramírez Saizar, La venganza de Nandayure (San José, Costa Rica: Editorial “La Nación,” 1950). Según Carlos Calvo Gamboa, las plantaciones de banano afectaron negativamente la producción de granos en Guanacaste, Puntarenas y la costa del Pacífico sur, porque atrayeron fuerza laboral de las tradicionales zonas de cultivos, lo cual llevó a una crisis de subsistencia y a la importación de granos por parte del estado. La guerra mundial que estalló en 1939 agravó todavía más la escasez de productos de subsistencia. Ver Carlos Calvo Gamboa, León Cortés y su época (San José, Costa Rica: EUNED, 1982), 74. 


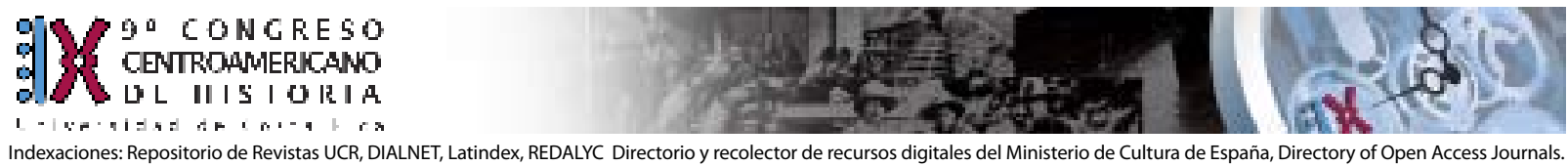

Indexaciones: Repositorio de Revistas UCR, DIALNET, Latindex, REDALYC Directorio y recolector de recursos digitales del Ministerio de Cultura de España, Directory of Open Access Journals. Diálogos Revista Electrónica de Historia ISSN 1409-469X. Número especial 2008. Dirección web: http://historia.fcs.ucr.ac.cr/dialogos.htm

de los guanacastecos y propuestas ante el gobierno y las instituciones estatales relativas a las políticas oficiales en la provincia. ${ }^{5}$ En enero 1935, cuando el periódico El Guanacaste —el vocero oficial de la La Casa de Guanacaste-comenzó a circular, los líderes de La Casa publicaron un informe de labores, que registraba actividades para apoyar las artes y la cultura en la región; promoción de nuevos cultivos entre agricultores guanacastecos; discusión de diferentes propuestas de leyes relacionadas con los problemas económicos y agrarios de la provincia; promoción de obras de urbanismo en Guanacaste; creación de células locales de La Casa; patrocinio de un proyecto de película sobre Guanacaste; entre otros. ${ }^{6}$

La Casa y el periódico El Guanacaste se convirtieron en medios principales para crear la comunidad de los promotores regionales y para elaborar el discurso y la identidad regionales. Los activistas de la Casa de Guanacaste se consideraban "abnegados hijos de la pampa residentes en San José”, que estaban realizando una misión árdua, patriótica y generosa a favor de su "tierruca lejana”, e invitaban a todos los guanacastecos a visitar La Casa, "el hogar de todos los guanacastecos” con un propósito común: la persecusión de bienestar y progreso para

\section{5}

La Casa de Guanacaste estableció sus estatutos y reglamentos, que fueron publicados en las páginas de El Guanacaste. Los estatutos determinaron aspectos como los afiliados, membresías, votación, representantes y la prohibición de actividades abiertamente políticas y religiosas dentro de la sociedad, tal y como lo demandaba la ley de asociaciones. El Guanacaste también publicó el himno de La Casa, "Marcha de la Casa de Guanacaste," escrito por José A. Ramírez Saizar. "Estatutos de la 'Casa de Guanacaste’," El Guanacaste, 1/4/1935. Entre los fundadores de La Casa estaban los abogados Alvarez Hurtado y Francisco Faerron; Ramón Zelaya; y los maestros Manuel Angel López Bonilla, Higinio Vega Orozco, Marcelino Canales, Mariano Salazar, Manuel Grillo, Zacarías Cháves, Francisco Carrillo, Fabio Carrillo, Juan Rafael López Bonilla, Alejandro García, Rubén Báez. “Casa de Guanacaste,” El Guanacaste, 18/8/1936, 1 y 6.

6

En un inicio, La Casa de Guanacaste cambiaba su junta directiva cada tres meses. En julio de 1935, los siguientes guanacastecos formaban la junta directiva: Salvador Villar (presidente), Manuel Angel López Bonilla (vice-presidente), Liborio Flores (secretario), Máximo Solano (pro-secretario), Rubén Báez (tesorero), Andrés Santana (fiscal) y, en calidad de vocales, Manuel Grillo, Rafael Gutiérrez y Matilde Gutiérrez. "Nueva Directiva de La Casa de Guanacaste,” El Guanacaste, 20/7/1935, 2. Sin embargo, muy rápidamente se reconoció que la elección de una junta directiva nueva cada tres meses era un factor de inestabilidad y, en enero de 1935, El Guanacaste informó en una pequeña columna que La Casa había estado experimentando "ocho días de anarquía”, ya que no había sido posible elegir la nueva Junta por la falta de quórum en la asamblea de la sociedad. "Ocho días de anarquía,” El Guanacaste, 20/1/1936, 2. La nueva Junta se eligió en la Asamblea del 19 de enero. “Nueva Directiva de 'La Casa de Guanacaste’, “ El Guanacaste, 1/2/1936, 1. Otra nueva Junta se eligió en octubre 1936. Esta vez, estaba compuesta del presidente Manuel Angel López Bonilla, vice-presidente Higinio Vega Orozco, secretario Marcelino Canales, pro-secretario Luis Montiel, tesorero José María Zúñiga Lupi, fiscal Fabio Carrillo, y el vocal Jesús Vega Orozco. El Guanacaste, 8/10/1936, 1. 
toda la provincia. ${ }^{7}$ Representar toda la provincia parecía una meta totalmente legítima y viable, hasta el extremo de que algunos líderes de La Casa de Guanacaste se consideraban los únicos representantes verdaderos de la unidad guanacasteca. ${ }^{8}$ Los líderes de La Casa se imaginaban promotores del regionalismo guanacasteco en un nuevo nivel, en el cual los guanacastecos serían llevados a adquirir conciencia de la situación particular de su provincia—la falta de atención por parte del gobierno central—y a tomar acción conjunta para corregir ese estado de asuntos injusto. La única forma de lograr las metas regionales consistía en abandonar las pequeñas disputas y entender que Guanacaste no era una provincia cualquiera, porque las demás provincias recibían siempre la atención del gobierno, sin ningún esfuerzo adicional, mientras que Guanacaste era siempre abandonada a su suerte. ${ }^{9}$ La única solución para los guanacastecos era unirse y obligar al gobierno a escuchar sus demandas, o—-todavía mejorresolver sus problemas por medio de una acción conjunta y coordinada. ${ }^{10}$ El Guanacaste también proclamaba la idea de que los habitantes de la provincia eran miembros de una gran familia, y por tanto los promotores del regionalismo eran obligados a proporcionar un ejemplo de fraternidad a aquellos que no creían en el proyecto regionalista. ${ }^{11}$

7

Liborio Flores, “De pié, Guanacastecos!,” El Guanacaste, 1/3/1935, 2. La emergencia de los periódicos regionales era un fenómeno común en muchos países en los años 1930. Para el caso de Finlandia, ver Jaana Hujanen, Journalismin maakunnallisuus. Alueellisuuden rakentuminen maakuntalehtien teksteissä ja tekijöiden puheessa (Tesis doctoral, University of Jyväskylä, 2000), 30-31.

8

Ver “'La Casa de Guanacaste’ es la verdadera y única abanderada del movimiento unionista en Guanacaste,” El Guanacaste, 20/7/1935, 1. Ver también, Francisco Leal, “¿Ilusos, locos o quijotes?” El Guanacaste, 10/7/1935, 3. Esta posición generó crítica por parte de algunos autores que publicaban en otros periódicos. Ver por ejemplo, “Dr. Baltodano y la Casa Guanacaste,” Diario de Costa Rica, 1/8/1935, 23.

9

Los promotores del regionalismo estaban conscientes de las rivalidades entre los habitantes de Liberia y los que vivían al sur del río Tempisque y llamaban a la búsqueda de los intereses comúnes entre los pueblos y las localidades. Según el Diario de Costa Rica, "Existe entre estos dos cantones [Liberia and Santa Cruz] un antagonismo infundado, el cual no debe convertirse en odio entre los habitantes, sino en aspiración de progreso de ambos pueblos.” Diario de Costa Rica, 5/1/1929, 6. Un buen ejemplo de los intentos de borrar las discordias fue la visita amistosa de los liberianos a Nicoya en 1929. Diario de Costa Rica, 5/4/1929, 4.

10

"No estamos en la misma condición de los demás provincianos hermanos que, unidas o no, siempre tendrán la solicita atención de los gobernantes.” "Editorial: La armonía guanacasteca y la nueva conciencia regional.” El Guanacaste, 10/10/1935, 1. Ver también El Guanacaste, 1/7/1936, 2.

11

Andrés Santana, uno de los editores del periódico, prefería hablar de una lucha de corazones y sentimientos. Ver A. Santana C., "La maleficencia," El Guanacaste, 1/4/1935, 2. 
Los regionalistas estaban preocupados por las divisiones y hasta "odio" entre las localidades guanacastecas, que, según ellos, eran una causa importante de la falta de progreso intelectual y material en la provincia. Un editor expresaba su preocupación por las rivalidades locales e insistía al mismo tiempo que los guanacastecos como personas compartían un carácter humano positivo y único. Esta construcción aparentemente contradictoria estableció un caracter común y único para todos los habitantes de la provincia como norma, que hacía posible exigir a los guanacastecos que honraran ciertos ideales regionalistas, lo que, al mismo tiempo, hacía posible que líderes regionalistas criticaran a sus "comprovincianos" si no se comportaban de manera adecuada o no cabían en esa supuesta forma natural del "ser guanacasteco".

El discurso de unidad y armonía se empleaba también como instrumento para mantener el regionalismo distante del tema de los conflictos sociales en la provincia. En 1936, la columna editorial de El Guanacaste declaró que los guanacastecos eran gente honesta que valoraban una remuneración adquirida de manera honesta y que, debido a esa característica común, lo patrones guanacastecos no eran capaces de abusar de sus peones, quienes, por su parte, no pensaban que su patrón les estaba robando. Gracias a la voluntad divina, existía una armonía total entre empleadores y trabajadores. ${ }^{12}$ Este discurso de armonía, por un lado, borraba el problema agrario y el creciente conflicto social en la provincia y, por el otro, definía las reglas que los patronos y los trabajadores debían respetar para contribuir a la concordia y la unidad en la región, que era su obligación como guanacastecos. ${ }^{13}$ Algunos editores de El Guanacaste estaban preocupados por el problema de las tierras, y otros hasta cuestionaban los niveles de explotación en Guanacaste en 1935, pero no había una línea editorial definida con respecto a estos aspectos. Los editoriales trataban la situación problemática del agro guanacasteco en

12

"Los guanacastecos damos infinitas gracias a la Providencia de que nuestro pueblo practique honestamente todavía este precepto y por ello existe allá una casi total armonía entre los patrones, por lo general considerados e incapaces de mezquinos abusos, y sus buenos peones y empleado en cuyas mentes no priva el prejuicio de que se les roba, ni están pensando en que los haberes del patrón les pertenece...” “Editorial: ¡Feliz año nuevo!,” El Guanacaste, 1/1/1936, 1.

13

Otros autores buscaban maneras no confrontativas de analizar las relaciones de clase en Guanacaste, como el seudónimo Minos Gracel, quien muy respetuosamente solicitaba a los terratenientes pagar mejores salarios a los peones y sabaneros: "pedimos, con todo respeto, a los patrones de las haciendas guanacastecas, lo mismo que a las industrias, etc. aumento de salarios a peones y sabaneros, seguro de vida para los trabajadores, y buena alimentación. El peón y el sabanero es todo un programa de lucha que trataremos de seguir." "El peón y el sabanero,” El Guanacaste, 10/4/1936, 3. 
formas que solían buscar a los culpables no dentro de la provincia sino en el gobierno central. ${ }^{14}$ La solución al problema de tierras tenía que venir desde el gobierno central, por cuanto se trataba de la paz social y la democracia. A veces, el periódico publicaba artículos de sus lectores, que ofrecían otra perspectiva sobre el problema agrario de Guanacaste, ${ }^{15}$ sin embargo la línea editorial cultivaba una visión de armonía al interior de la provincia. Además, al escribir en el periódico regionalista, era típico por parte de los hacendados girar la atención de los problemas sociales a la cuestión de la falta de carreteras y vías férreas. ${ }^{16}$ Confrontaciones abiertas de distintas posiciones no eran comúnes en las páginas de El Guanacaste. Lo usual eran las exhortaciones a la armonía y unión de todos los guanacastecos como comunidad y a la honestidad, integridad y persistencia como individuos.

Aunque los líderes de La Casa y los editores de El Guanacaste estuvieran convencidos de que promovían un movimiento y una ideología totalmente nueva, la realidad es que el discurso regionalista de la segunda mitad de los años treinta continuaba siendo heterogéneo, aunque era más elaborado y organizado que los discursos de la década anterior. Este "nuevo" regionalismo guanacasteco continuaba por el mismo camino, dibujado a inicios del siglo: la denuncia de la discriminación de Guanacaste dentro de la nación.

La falta del progreso infraestructural en la provincia era el tema principal de El Guanacaste, y la discusión se convertía cada vez más crítica y confrontativa. En 1936, El Guanacaste repetía lemas en su portada que se referían a la falta de ferrocarriles y proyectos de carreteras.

14

“Como se ve, el problema agrario en Guanacaste presenta caracteres que hacen imperativa la acción del Estado, con una política bien definida a favor del parcelamiento de la tierra a fin de aumentar el número raquítico de propietarios. La República no puede permanecer indiferente... porque el problema, grave desde ahora, tiende fatalmente a agudizarse con el correr de los años, y la paz social y los atributos de la democracia costarricense desparecerán conforme aumente en intensidad el problema que entraña una mala división del agro nacional.” "Editorial: El complejo agrario de Guanacaste enfocado desde nuestro punto de vista. Parecelamiento de la tierra. Financiación de las siembras y un mercado para cosechas.” El Guanacaste, 10/11/1935, 1.

15

Guido Acevedo describía a los campesinos como “arruinados por la ambición codiciosa, torpe y hostil de muchos propietarios latifundistas. ¿Por qué esos hombres que hoy gozan de grandes extensions no le facilitan un pedazo de terreno al pobre trabajador, que hoy se lamenta habiendo sido arruinado por ellos mismos?” Medardo Guido Acevedo, “Fases regionales del Guanacaste, ” El Guanacaste, 10/11/1935, 4. Guido Acevedo trabajaba como maestro de primaria en Bagaces.

16

"Deben acostumbrarse las gentes a la idea de que Guanacaste no queda tan lejos como Asia o Africa," El Guanacaste, 8/7/1936, 6. 


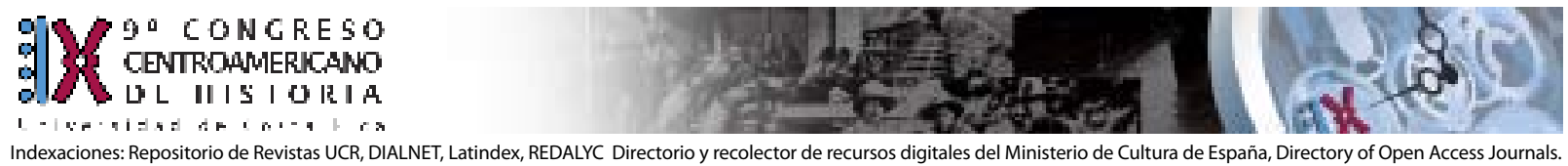

Indexaciones: Repositorio de Revistas UCR, DIALNET, Latindex, REDALYC Directorio y recolector de recursos digitales del Ministerio de Cultura de España, Directory of Open Access Journals. Diálogos Revista Electrónica de Historia ISSN 1409-469X. Número especial 2008. Dirección web: http://historia.fcs.ucr.ac.cr/dialogos.htm

Los títulos de las columnas también repetían que Guanacaste era la única provincia en Costa Rica sin ferrocarriles u otras rutas de comunicación viables. ${ }^{17}$ La falta de carreteras y ferrocarriles se consideraba como el obstáculo principal para lograr progreso en Guanacaste. Constantemente, se comparaba Guanacaste con las otras provincias y se acompañaban con estadísticas que detallaban el atraso infraestructural de la provincia en contraste con el progreso del Valle Central. ${ }^{18}$ Con el fin de reducir el desempleo generado por las consecuencias de la depresión mundial, el gobierno incrementó la inversión en las obras públicas, sin embargo, poco de esta inversión salió del Valle Central. La política de la construcción de carreteras generó grandes expectativas en los guanacastecos, quienes inicialmente confiaban en que su provincia recibiría en justa proporción su parte del progreso, sin embargo, muy pronto se frustaron por la falta de ejecución de las obras en la provincia. ${ }^{19}$ El resto de los caminos en la provincia eran de tierra. ${ }^{20}$

17

"Ni una vara de camino se ha construido en el Guanacaste con el sobreimpuesto de los cigarrillos destinado a ese fin", El Guanacaste, 1/1/1936, 2. "La Provincia de Gte no tiene verdaderas vías de comunicación," El Guanacaste, 10/6/1936, 1.

18

"La acción de los futuros diputados,” El Guanacaste, 1/1/1936, 2. Ver también, “Notas amargas,” El Guanacaste, 1/6/1936, 1. Un columnista en 1936 comparó Tilarán con Limón y argumentó que Tilarán podría convertirse en productor de banano todavía más importante que Limón. Con un ferrocarril—proyecto que había sido cerrado por diputados miopes, apesar de haber sido la visión clara del Secretario de Obras Públicas y el futuro presidente León Cortés-Tilarán podría estar exportando bananos de mayor calidad que las que se producían en Limón. "Sierra de Tilarán. El banano y su larga vida de plantación,” El Guanacaste, 10/4/1936, 2. Naturalmente, las noticias de los planes del gobierno de construir ferrocarril en el pequeño pueblo de Puriscal en la región central molestaba a los editores de El Guanacaste, quienes declaraban que mientras Puriscal era solo una "hacienda", Guanacaste representaba el granero de la nación y, por tanto, un ferrocarril a Guanacaste era mucho más justificado que uno a Puriscal. “Editorial: Quique Suum”, El Guanacaste, 8/8/1936, 1. Como se ha mencionado anteriomente, es cuestionable si Guanacaste realmente era granero de Costa Rica. Además, no se construyó ningún ferrocarril a Puriscal.

19

A finales de la década de 1930, había 653.5 kilómetros de diferentes tipos de caminos pavimentados (asfalto, macadam, concreto) en el país, y solo 16 kilómetros de esos estaban en Guanacaste y eran macadamizados. Calvo Gamboa, León Cortés y su época, 31. Según Carolyn Hall, en 1924, no había carreteras de asfalto o concreto en Costa Rica, pero, hacia 1940, un total de 365 kilómetros eran de esos materiales. En 1924, aproximadamente 150 km, y en 1940, 423 km de las carreteras del país eran de macadam y gravel. Carolyn Hall, Costa Rica: A Geographical Interpretation in Historical Perspective (Dellplain Latin American Studies, no. 17(Boulder and London: Westview Press, 1985), 129.

20

Durante la administración Cortés se gastaron 25.388.543 colones en obras públicas, un 7\% de ellos, en Guanacaste. De los 1.838.108 colones invertidos en la provincia, 732.710 se gastaron en la construcción de edificios gubernamentales (incluyendo el edificio de la comandancia en Liberia), 318.051 en escuelas y el resto, 
Adicionalmente al reclamo tradicional por la atención del gobierno, apareció una nueva forma de ver el problema, que exhortaba a los guanacastecos que dejaran de lloriquear y se levantaran su autoestima. De acuerdo con esta visión, en vez de lamentar y compadecerse, los habitantes de la provincia tenían que levantarse en acción y demandar sus derechos como miembros plenos de la nación. El primer número de El Guanacaste en enero de 1935 llamaba la misión de La Casa de Guanacaste y del periódico "Marcha sobre Roma”, y describía el movimiento político como una cruzada religiosa, pues se estaba predicando "el nuevo Evangelio, el Evangelio de la Unión Guanacasteca". Se llamaba a los promotores del regionalismo "el batallón de los vencedores en marcha” y se demandaba a los guanacastecos dejar de quejarse de que Guanacaste había sido abandonado por el gobierno central. ${ }^{21}$ Algunos columnistas iban todavía más lejos en el uso del lenguaje de provocación, pues llegaban a expresar que los guanacastecos eran los principales responsables del atraso de la provincia, porque su indiferencia con respecto a los problemas de la provincia y su irresponsable lealtad hacia políticos que no eran guanacastecos ni genuinamente interesados en resolver los problemas de la región. ${ }^{22}$ Con la creación de La Casa de Guanacaste y el periódico El Guanacaste, el incipiente movimiento regionalista guanacasteco se puso cada vez más impaciente en su relación con el gobierno nacional. Los guanacastecos no iban a esperar más, sino que se preparaban para tomar por su propios medios lo que no habían logrado por medio de las políticas gubernamentales.

El llamado a dejar de lamentarse y esperar fue cada vez más común en las páginas de $E l$ Guanacaste. El proceso de elaboración del discurso regionalista desde los primeros años del siglo veinte había alcanzado una maduración programática: ya había aparecido un contingente de guanacastecos dispuestos a comprometerse con una lucha política organizada por los intereses (que consideraban ser) de la provincia. Esta maduración tuvo mucho que ver con el regreso de Francia del doctor Francisco Vargas Vargas, quien, al partir a estudiar medicina, había jurado que regresaba para luchar por el progreso de su provincia.

en caminos, puentes, tuberías y cañerías. Calvo Gamboa, León Cortés y su época, 73. La desilusión de los guanacastecos con León Cortés fue profunda, y muy pronto la organización comenzó a criticar abiertamente al gobierno.

21

Ver, El Guanacaste, 1/1/1935.

22

Ver A. Alvarez Hurtado, “De nuevo,” El Guanacaste, 1/1/1935, 2; ver también, Andrés Santana C., “No más lamentaciones," El Guanacaste, 10/7/1935, 1-2; “Llamamiento a los Guanacastecos," El Guanacaste, 1/1/1935, 4 y “El Paraíso de Mahoma,” El Guanacaste, 1/3/1935, 1. 


\section{El Partido Confraternidad Guanacasteca y el doctor Vargas Vargas}

Francisco Vargas Vargas nació en una familia de terratenientes en Carrillo, Guanacaste en 1909. Vargas Vargas se interesó en política desde niño y sus primeros escritos fueron publicados en periódicos cuando tenía solo diez años. ${ }^{23}$ Se graduó de doctor en medicina en la Sorbona, Francia, y comenzó a trabajar en el Hospital San Juan de Dios en la ciudad capital en 1935. ${ }^{24}$ Sin embargo, un enfrentamiento serio con sus superiores lo hizo dejar su puesto en el Hospital en mayo 1936, viajar a Guanacaste y declarar que iba a su provincia siguiendo la voluntad de su corazón de servir a sus comprovincianos y a la humanidad. ${ }^{25}$ En el tiempo de la fundación del Partido Confraternidad Guanacasteca en diciembre 1937 y de la primera campaña electoral, el doctor Vargas ya se había hecho conocer como un médico excelente, quien, usualmente atendía pacientes pobres gratis y quien viajaba por toda la provincia y enseñaba a los pobres del campo a leer y escribir. Así, ya antes de la fundación del partido y el comienzo oficial de la campaña electoral, el doctor Vargas había estado constantemente presente en las páginas de El Guanacaste. El Consejo Editorial del periódico lo apoyaba activamente y, cuando llegó el momento de la organización política, Vargas se había convertido de manera espontánea en $\boldsymbol{E} \boldsymbol{L}$ candidato del Partido Confraternidad Guanacasteca.

Muy pronto después de su fundación, el Partido Confraternidad Guanacasteca experimentó un éxito significativo en su primera participación electoral en 1938 y, en opinión de muchos militantes y observadores, iba a convertirse en una fuerza política importante en escala nacional; no obstante, perdió rápidamente su posición en el escenario electoral después de 1939. El Partido no ha sido un objeto de investigación atractivo para los estudiosos de la historia política de Costa Rica, ni siquiera para los que se han dedicado a investigar la historia de los partidos políticos en el país. Esto se debe, probablemente, al hecho de que la investigación sobre la historia política de Costa Rica se ha realizado básicamente desde el centro del país y con el

23

De acuerdo con Carlos Dávila, Vargas escribía artículos en la La Prensa Libre cuando tenía apenas diez años de edad. Ibid., 41.

24

“La incorporación del Dr. Francisco Vargas V.,“ El Guanacaste, 1/12/1935, 1.

25

Vargas realizó una operación de emergencia estando fuera de turno, lo cual llevó a sus superiores en el Hospital San Juan de Dios a amonestarlo. El Guanacaste, 20/5/1936, 1. 
presupuesto de que las únicas organizaciones políticas realmente importantes en la historia de Costa Rica han sido los partidos con asiento en el Valle Central. No ha habido interés en analizar las políticas nacionales desde las perspectivas regional, provincial o local. ${ }^{26}$ Visto desde Guanacaste, el Partido Confraternidad Guanacasteca desempeñó un papel notable en las políticas nacionales de los últimos años de la década de 1930. Fue capaz de movilizar amplias masas de población pobre, los sectores medios e, incluso, a algunos de los representantes de la clase terrateniente en Guanacaste, y generó grandes expectativas-especialmente, entre las clases bajas - y temores — en los grupos poderosos en los ámbitos provincial y nacional. Sin embargo, el sueño del líder del partido Francisco Vargas Vargas de crear un amplio movimiento político sin barreras sociales nunca se realizó.

Carlos Dávila ha identificado tres distintos sectores de simpatizantes y militantes del Partido Confraternidad Guanacasteca. Primero, estaba la clase media; profesionales, comerciantes y medianos finqueros, jóvenes prometedores, ávidos de romper los límites impuestos por las oligarquías locales. Ellos eran los miembros y líderes más activos del partido. El segundo sector consistía en dos grupos de terratenientes: aquellos que, sin ser activistas, apoyaban financieramente al partido; y aquellos grandes terratenientes y otras figuras que habían estado perdiendo su influencia en el ámbito provincial o local y decidieron involucrarse en el movimiento por razones oportunistas. ${ }^{27}$ El tercer sector, de acuerdo con Dávila, eran los “seguidores fanáticos” de los sectores pobres: jornaleros, sabaneros, empleadas domésticas, arrieros, agricultores pobres y otros grupos de clases bajas y trabajadoras. ${ }^{28}$

26

El estudio de Carlos Dávila sobre el líder del Partido Confraternidad Guanacasteca, Francisco Vargas Vargas, realizado en la década de 1970 con base en entrevistas y fuentes periodísticas, es el único estudio histórico sobre este partido político regionalista y su líder. Carlos Dávila Cubero, ¡Viva Vargas! Historia del Partido Confraternidad Guanacasteca (San José, Costa Rica: Ediciones Guayacán, 1987). Por otro lado, solo la guerra civil de 1948 ha generado estudios con fuente oral y sobre las experiencias de los participantes de las regiones periféricas del país.

27

Agregaría a este grupo algunos representantes de los “nuevos ricos” de Guanacaste, como el caso de Francisco Cubillo Incer, quien no provenía de las familias terratenientes tradicionales de Guanacaste, sino que era originalmente un inmigrante nicaragüense pobre, quien, sin embargo, logro amazar una fortuna impresionante en laprovincia y convertirse en el "propietario de Filadelfia" a mediados de los años de 1920. Para más información sobre Cubillo Íncer, ver Marc Edelman, "Don Chico y el diablo: dimensiones de etnia, clase y género en las narrativas campesinas guanacastecas del siglo XX", en El paso del cometa: estado, política social y culturas populares en Costa Rica, 1800-1950, editado por Iván Molina y Steven Palmer (San José, Costa Rica: Plumsock Mesoamerican Studies and Editorial Porvenir, 1994).

28 Dávila, ¡Viva Vargas!, 59-60. 
La mayoría de los grandes terratenientes y hacendados tradicionales de Guanacaste nunca apoyaron al Partido. En tiempos del creciente conflicto social en la provincia, los hacendados desconfiaban de los militantes del Partido, quienes enfatizaban en los aspectos relacionados con los niveles crecientes de explotación de los pobres de la provincia. Solo las demandas por obras públicas en la provincia acarrearon apoyo por parte de las elites terratenientes, quienes necesitaban de carreteras para transportar sus productos a los mercados del Valle Central. Como se ha visto anteriormente, algunos hacendados y sus representantes publicaban frecuentemente columnas en El Guanacaste, en las cuales participaban en la promoción del regionalismo y exponían los clásicos reclamos del abandono provincial para legitimar sus necesidades de carreteras y ferrocarriles. ${ }^{29}$ En contraste, prácticamente no hubo voces subalternas que aparecieran directamente en El Guanacaste, el órgano del movimiento político, a pesar de que se consideraba que las clases pobres eran la base social del Partido Confraternidad Guanacasteca. Es notablemente difícil encontrar algún testimonio que se refiriera a la participación de las clases bajas — o su decisión de no participar —en el movimiento político guanacasteco. Los militantes del Partido más visibles en las fuentes accesibles son todos de sectores de clase media: intelectuales, finqueros, comerciantes y, especialmente, educadores. Ellos formaban el consejo editorial del periódico y escribían en él; ellos lideraban el movimiento regionalista y su entrada en la política electoral.

El Partido Confraternidad Guanacasteca fue inscrito como partido electoral en junio 1937, y su primera convención fue la de Llano Grande de San Miguel en diciembre 1937. ${ }^{30}$ Entre 2500 y 5000 personas asistieron la reunión para elegir a los candidatos del partido para las elecciones nacionales. ${ }^{31}$ El primer candidato al Congreso era el doctor Francisco Vargas Vargas y los demás tres fueron Lisímaco Leiva Cubillo, Hernán Vargas Castro y Adán Guevara Centeno. ${ }^{32}$ El Partido Confraternidad Guanacasteca participó en tres campañas electorales: las elecciones del medio período del Congreso de 1938; las elecciones presidenciales y del Congreso de

29

Ver, por ejemplo, Francisco Faerron, “Carretera panamericana I,” El Guanacaste, 1/3/1936, 1. 30

Según Dávila, la primera Asamblea General del partido se llevó acabo en julio 1937. Dávila, ¡Viva Vargas!, 71. 31

Dávila agrega que posiblemente hubo todavía más gente en la reunión. Ibid., 61. 32

“La gran convención,” El Guanacaste, 5/12/1937, 1. 
1940; y las elecciones del medio período del Congreso de 1942.33 Cuando Vargas Vargas comenzó su campaña en Guanacaste, las autoridades locales—o simpatizantes del partido oficial-interrumpían o prohibían sistemáticamente sus reuniones y plazas políticas. ${ }^{34} \mathrm{Al}$ informar sobre la tensa campaña electoral en Guanacaste, los periódicos mostraban un rostro de cultura política local muy diferente de los relatos oficiales del carácter pacífico y civilizado de la democracia costarricense.

El doctor Vargas inauguró su campaña en 1937 llamando a los guanacastecos a acompañarlo en la "hora del sacrificio", ya que había llegado el momento de la redención. El anuncio en El Guanacaste se dirigía a los jornaleros, sabaneros, agricultores y ganaderos por medio de un lenguaje bíblico. Vargas Vargas se comparó con Cristo y ofrecía redención a todos los guanacastecos, pobres y ricos. La provincia había estado abandonada por el gobierno por ciento quince años, y ahora había llegado la hora de levantarse y tomar acción: “Abajo los traidores de las ideas de Cristo!”-aclamaba Vargas. Los principales puntos del discurso político del doctor Vargas se anunciaban en un campo pagado del Partido, que denunciaba el sufrimiento de los guanacastecos como clase explotada y como habitantes de una provincia expulsada del vagón de la modernización:

“El Guanacaste comienza a hacerse sentir gracias al Partido Unión y Confraternidad Guanacasteca:

Peones. Sabaneros. Agricultores. Ganaderos.

Es la hora del sacrificio.

El momento de nuestra redención ha llegado.

Nuestra vida ha sido siempre:

Trabajo. Taquilla y tumba prematura.

Ahora debemos unirnos para que se nos trate como a los demás pueblos de Costa Rica.

33

Dávila, ¡Viva Vargas!, 83.

34

Ibid., 77. 
Queremos hospitales, carretera y segunda enseñanza, como las otras provincias.

Hace 115 años vivimos en el abandono y miseria más absolutos.

Hombres del Guanacaste: Ser o no ser. Guanacaste! Levántate y anda...!

¡Abajo los traidores de las ideas de Cristo!”35

Las denuncias de Vargas Vargas sobre la pobreza y sus llamados a la redención colectiva podían sonar radicales. Ya desde antes de ser electo como candidato principal del Partido Confraternidad Guanacasteca, Vargas había enfrentado acusaciones de ser comunista. En octubre 1937, Vargas declaró que no contestaría más a acusaciones personales, ya que "el destino de 67 mil personas estaba en juego”. Según Vargas, después de 115 años de ciudadanía costarricense, los guanacastecos continuaban viviendo sin hospitales, carreteras o escuelas secundarias. Pareciera que Vargas creía sinceramente en que él solo podía redimir a los guanacastecos de la discriminación y el abandono centenarios. Al rechazar las acusaciones de que él agitaba a las clases bajas contra los ricos de la provincia, Vargas mostraba telegramas de apoyo que recibía de los guanacastecos ricos, de hacendados e intelectuales. Por ejemplo, Vargas publicó un telegrama que decía lo siguiente: "Mienten los que digan que Ud. o sus compañeros pretenden sublevar peones contra patrones. Tanto los primeros como los últimos abrazamos con entusiasmo la causa de "Fraternidad y Unión Guanacasteca", que es la defensa y salvación de esta provincia." ${ }^{36}$ Nueve personas firmaban el telegrama y Vargas añadía su comentario: "Nota: Todos los abajo firmados en su mayoría son finqueros. Entre ellos está uno de los capitalistas más fuertes de Guanacaste, don Francisco Cubillo Incer.”37 Vargas publicó otros telegramas de guanacastecos prósperos, incluyendo algunos de señoras pudientes, para sugerir que si la gente rica lo estaba apoyando, era imposible que él fuera comunista. Vargas se llamaba socialista cristiano y afirmaba que él había desarrollado ideas políticas claras a la edad de doce años (según él, algunos de sus escritos de esa edad fueron luego publicados cuando él tenía quince años), cuando en Costa Rica no había comunismo:

$35 \quad$ El Guanacaste, 17/10/1937, 2.

36 El Guanacaste, 17/10/1937, 5.

37

Ibid. Cubillo Incer era uno de los mayores abastecedores de novillos en los mercados ganaderos del Valle Central, y proveía entre 1 y 3\% del total del ganado nacional en el período de 1920 a 1948. Marc Edelman, "Don Chico y el diablo," 112-113. 
"Nunca he leído a Karl Max [sic]. Pero mi profesión de médico, la cual he tratado de santificar con un verdadero apostolado, me ha permitido palpar tantas miserias, iniquidades e injusticias, como se cometen, no sólo con los menesterosos, sino también con los que tienen dinero abusando de su ignorancia Clamar justicia para ese conglomerado social, como para los médicos que estamos dispuestos a tomar el buen camino de la ética profesional, no es cosa que adolezca de extremismo alguno.”38

Vargas rechazaba la acusación de ser comunista y explicaba que sus convicciones se debían a su profesion de médico, pues había observado mucha miseria e injusticia, ${ }^{39}$ y nuevamente comparaba a su persona con la de Cristo: "Y no es favor el que se me haría eligiéndome diputado. Estoy sacrificando mi vida, mi trabajo y haberes, por esta causa, por la misma que murió Cristo hace 1937 años.”40 En la misma página de El Guanacaste se encontraba un ensayo que pedía a los que acusaban a Vargas de ser agitador comunista demostrar evidencia de odio y lucha de clases en su organización. De acuerdo con el autor, tal evidencia no existía, porque prácticamente todos los sectores sociales estaban involucrados en el Partido como activistas y seguidores: agricultores, comerciantes, industriales, representantes del gran capital; pequeños finqueros y propietarios; gente de clase media, trabajadores, mujeres y sabaneros. ${ }^{41}$ Era totalmente claro que el lenguaje de la campaña electoral del doctor Vargas

38

“No soy comunista. Soy Socialista Cristiano,” El Guanacaste, 17/10/1937, 5 y 6.

39 El fenómeno del "populismo médico” era común en muchos países latinoamericanos en los años 1920 y 1930, cuando los reconocidos médicos-políticos estudiaban las condiciones de salud de la población pobre con el fin de diseñar políticas públicas reformistas cuando estuviesen en el poder. El médico chileno Salvador Allende había vivido en los arrabales de Santiago cuando era estudiante de medicina a finales de la década de 1920. Otros ejemplos de influyentes médicos-políticos eran Arnulfo Arias en Panamá; Ramón Grau San Martín en Cuba, y Juscelino Kubitschek en Brazil. Steven Palmer, From popular medicine to medical populism: doctors, healers, and public power in Costa Rica, 1800-1940 (Durham: Duke University Press, 2003), 218-219. En Costa Rica, los doctores Moreno Cañas y Calderón Guardia pueden mencionarse como ejemplos representativos de médicos políticos con posiciones reformistas o populistas. En Guanacaste, el doctor Vargas de ninguna manera fue el primer médico en preocuparse por los pobres, pues el doctor Bernardo Nobo, el dueño de la Botica La Central en Liberia, anunciaba el horario de atención a los pobres en las noches en el año 1900. Ver La Vanguardia, 24/10/1900, 4.

40

“No soy comunista. Soy Socialista Cristiano,” El Guanacaste, 17/10/1937, 6. 41

Ibid. 
estaba íntimamente ligado al discurso de movimiento regionalista más amplio representado por La Casa de Guanacaste y el periódico El Guanacaste. Entre los puntos comunes más fuertes estaba el lenguaje de conciliación de clases, que prevalecía en los discursos proselitistas y las declaraciones electorales, columnas y opiniones de los periodistas regionalistas, independientemente de su posición política específica.

Recurrentes incidentes de violencia marcaron la primera campaña electoral del Partido Confraternidad Guanacasteca, y el gobierno central decidió enviar tropas a Guanacaste unos pocos días antes de las elecciones para que "garantizaran el orden” en la provincia. También se envió la Cruz Roja, en caso de que hubiese problemas. ${ }^{42}$ En vez del ambiente violento y el fraude electoral, el Partido Confraternidad Guanacasteca salió sorprendentemente bien en las elecciones de medio período de febrero de 1938 y logró obtener un escaño—para el doctor Vargas—para el período 1938-1942. El fraude electoral causó amargura entre los líderes y los seguidores del partido. Sin embargo, para celebrar el éxito del doctor Vargas se declaró que, "El caudillo de las pampas doctor Vargas rompió el dique que durante más de cien años había conservado figurones improvisados y políticos bribones en el Guanacaste...”." 43

En el grabado de la primera plana que decoraba el periódico El Guanacaste después de las elecciones, el líder victorioso doctor Vargas se dibujaba como un cowboy macho montando a caballo con una pistola de considerable tamaño en su cartuchera. El caballo tenía una mirada sabia y estaba de patas traseras y el macho Vargas parecía estar a punto de tomar su arma. La ilustración resultaba impresionante, ya que, durante la campaña electoral, el doctor Vargas había caído del caballo y se había dañado seriamente la columna. Vargas fue sometido a varias y largas operaciones y períodos de tratamiento en los Estados Unidos, y nunca se recuperó totalmente de las lesiones, hecho que resultó fatal también para el Partido.

A pesar del fraude, el Partido ganó en Guanacaste, lo cual incitó euforia y grandes expectativas en sus seguidores y militantes. Aunque los líderes del partido denunciaban que el fraude les había quitado votos, ellos mismos parecían estar desconcertados por el éxito de Vargas. Pero ese éxito no duraría mucho. En las elecciones posteriores (1940, 1944, 1946 y 1948) 42

"Según la 'Prensa Libre' del 25 de enero, el Gobierno va a mandar al Guanacaste, una brigada de primeros auxilios en prevención de posibles incidentes...” El Guanacaste, 6/2/1938, 1; “La hora se aproxima,” El Guanacaste, 13/2/1938, 1.

43 El Guanacaste, 27/2/1938, 1. 
el Confraternidad Guanacasteca no obtuvo un solo escaño en el Congreso. ${ }^{44}$ Si en 1938, el partido recibió el 5.4\% del total de votos en todo el país, en 1942, la cantidad fue solo un 2.5\%. ${ }^{45}$ En las elecciones presidenciales de 1940, el Confraternidad Guanacasteca todavía obtuvo un $5.8 \%$ de los votos nacionales, de los cuales, un $2.3 \%$ correspondía a los votos de la provincia de Guanacaste. Pero en ese mismo año, el candidato del partido oficial Rafael Angel Calderón Guardia-otro médico-recibió un 84.3\% de los votos totales en Costa Rica, de los cuales un 8.2\% correspondía a guanacastecos que apoyaban a Calderón Guardia. ${ }^{46}$ Tres y media veces más guanacastecos votaron por Calderón Guardia que por Vargas Vargas, quien—se suponía — era el candidato de la provincia. Después de eso, el Partido prácticamente desapareció del escenario electoral nacional. El increíble éxito del nuevo partido regionalista en 1938 se convirtió en un mera nota al pie de página de la historia política de Costa Rica; no se trataba del sol naciente de la redención sino de un simple estrella fugaz que desapareció antes de recibir altura importante. ${ }^{47}$

Mientras tanto, los hacendados guanacastecos con carrera política en el Congreso la hacían dentro de los partidos políticos nacionales en vez de unirse al Partido Confraternidad Guanacasteca. En su anhelo de atarse a las fuerzas políticas más importantes del centro del país, continuaron el patrón de alineación con el poder central, el cual las elites guanacastecas habían seguido desde el siglo diecinueve. Por ejemplo, en el período del 1936 al 1948, cuatro congresistas guanacastecos_-Aristides Baltodano Briceño, Alvaro Cubillo Aguilar, Ramón Leiva Cubillo y Matías Sobrado García_representaban el partido oficial, mientras que el representante del Confraternidad Guanacasteca — el doctor Vargas, en el Congreso de 1938 al 1942 - era el único guanacasteco en la oposición. ${ }^{48}$ A pesar del discurso conciliador de clase

44

Jorge Mario Salazar Mora, Crisis liberal y estado reformista: análisis político-electoral (1914-1949) $1^{\text {a }}$ ed., Colección Historia de Costa Rica (San José, Costa Rica: Editorial de la Universidad de Costa Rica, 1995), 316. 45

Ibid., 317.

46

Ibid., 202 y 313.

47

Ya durante la campaña presidencial de 1939, el doctor Vargas había declarado que ya no tenía partido. El Guanacaste, 3/9/1939, 3.

48

Salazar, Crisis liberal y estado reformista, 315. 
de Vargas, el partido regionalista no fue capaz de lograr apoyo de los detentadores de poder regional, quienes tradicionalmente habían dado su apoyo a los partidos oficiales.

¿Por qué este partido político regionalista cayó tan rápido? ¿Por qué el Partido Confraternidad Guanacasteca no logró más victorias en las elecciones posteriores a 1939? Múltiples factores contribuyeron a los hechos, sin embargo, dos de los obstáculos más importantes para la expansión y consolidación del movimiento tenían que ver, por un lado, con el modo en que el partido construyó su liderazgo y, por el otro, la coyuntura política más amplia en el país a finales de los años 30 y principios de los 40. El partido dependía de la figura de caudillo del doctor Vargas, quien era visto como el redentor de la provincia; no se prepararon nuevos líderes ni se hizo propaganda para otras figuras dentro del partido. Toda la atención y todas las esperanzas se fijaron en el doctor Vargas, aunque después de la campaña de 1938 quedó claro que él estaba demasiado enfermo para llevar a cabo todo el trabajo político. En mayo 1939, la Asamblea Nacional aprobó un permiso para el diputado Vargas para ausentarse de las sesiones hasta que estuviera totalmente recuperado. Una vez más, Vargas viajó a Estados Unidos para someterse a una difícil cirugía, y sus seguidores y los militantes del partido se quedaron esperando su retorno. ${ }^{49}$ Durante los momentos cruciales de la temprana campaña en 1939, el partido no tenía la capacidad de tomar decisiones en la ausencia de Vargas. ${ }^{50}$ El Guanacaste describía la atmosfera entre los seguidores de Vargas, quienes esperaban el regreso de su jefe y recordaban los momentos gloriosos del pasado reciente del partido:

"El Guanacaste espera desesperadamente a su Jefe, quien manda la palabra en toda la provincia guanacasteca... El doctor Vargas Vargas vendrá muy pronto a orientarnos bajo una hermosa convención, como la efectuada en el Llano Grande de San Miguel y entonces sabremos cuál va a ser nuestra situación política en el Guanacaste... Esperamos la nueva orientación que nos trae nuestro Jefe del Guanacaste el Dr. Don Francisco Vargas Vargas, para alistar nuestras baterías.”51

La decisión de simplemente esperar que Vargas estuviera de regreso era perjudicial en si y,

49 "Permiso indefinido concedió el Congreso al Dr. Vargas hasta su total restablecimiento," El Guanacaste, 14/5/1939, 1 .

50 “A un grito de ESPERAMOS AL DR. VARGAS contestan los CONFRATERNOS a los políticos bribones,” El Guanacaste, 14/5/1939, 2.

51 Narciso Canales, “El Guanacaste y la política,” El Guanacaste, 21/5/1939, 2. 
a la vez, indicativa de los problemas subyacentes que hundirían al partido en los años 1940. Algunos militantes tuvieron claro del peligro que presentaba el momento, sin embargo, no fueron capaces de tomar acciones pertinentes sin la presencia del caudillo. Lo único que hicieron fue pedir a los demás hombres que salvaran el Confraternidad Guanacasteca:

"Alerta hermanos guanacastecos, no dejemos morir una causa tan noble que con tanto sacrificio, hasta con el de su salud nuestro dignísimo jefe el diputado doctor don Francisco Vargas V. fundara para salvación de nuestra Provincia, de no seguir sirviendo de escala a los políticos bribones, que por tanto tiempo la han escarnecido y humillado. Hoy que por estos mismos motivos nuestro distinguido jefe se encuentra lejos de su madre y familia, sus amigos y de la Patria, recluído en un hospital y soportando un lecho de penas, hoy es cuando La Confraternidad Guanacasteca debe ponerse de pie y sentir vibrar al unisono y de un solo sentimiento darle el respaldo que merece a las palabras ... desde Puerto Limón a los guanacastecos y así como muestra de lealtad y abnegación, a su regreso encuentre luchando como un solo hombre por la liberación de nuestro pueblo. Acordaos que mañana no debemos llorar como mujeres, lo que hoy no quisimos remediar como hombres por la inercia y el abandono." 52

La memoria de la euforia de la convención de 1937 y el triunfo electoral de 1938 estaba poderosamente fresca en la mente de los Confraternos, sin embargo, en la indefinida ausencia de Vargas, sus partidarios y seguidores no eran capaces de prepararse para las elecciones de 1940. Desde muy temprano de la campaña presidencial, quedó claro que el candidato oficial, Rafael Angel Calderón Guardia, contaba con una ventaja importante en la competencia electoral. Las fuerzas de la oposición trataron de formar un frente unido en su contra. La oposición—comunistas, intelectuales radicales, seguidores del expresidente Ricardo Jiménez, y los confraternos - denunciaban el autoritarismo de la administración Cortés, comparaban a Calderón con Hitler, y trataban de crear una coalición amplia para "defender la democracia” en el país. En mayo 1939, la convención del Partido Confraternidad Guanacasteca decidió apoyar al tres veces expresidente Ricardo Jiménez. El Guanacaste opinaba que con el apoyo a Jiménez, el Confraternidad demostraba que no estaban solo interesados en los problemas de la provincia de Guanacaste sino en los de todo el país. ${ }^{53}$

$52 \quad$ Jorge R. Caravaca C., "Carta abierta al Comité Provincial de la Confraternidad Guanacasteca en Liberia,” El Guanacaste, 14/5/1939, 2.

53 “La convención de la Confraternidad,” El Guanacaste, 14/5/1939, 2; “La Confraternidad Guanacasteca se DECLARÓ OFICIALMENTE RICARDISTA. Más de 8.000 hombres de la pampa y la montaña respaldan esa decisión,” El Guanacaste, 28/5/1939, 2. 
La salud del doctor Vargas empeoraba; sin embargo, retornó inesperadamente al país en junio y llamó a otra convención del partido en julio 1939.54 Esta vez, el Partido Confraternidad decidió participar en la creación de un nuevo frente para "combatir a los falanges de Mussolini y Hitler en Costa Rica”, que, según los líderes del Partido, representaba el candidato oficial de Cortés, doctor Calderón Guardia. ${ }^{55}$ La Alianza Democrática se presentaba como un partido de nuevo tipo (ideológico en vez de personalista) a pesar de que su candidato presidencial era el tres veces presidente y representante del Olimpo, Ricardo Jiménez. Algunos confraternos veían la Alianza como la continuación de la lucha que el partido había llevado a cabo en las elecciones del 1938. ${ }^{56}$ Sin embargo, muchos de los antiguos seguidores del Confraternidad Guanacasteca terminaron apoyando a Calderón Guardia, con lo cual ganaron el implacable reproche de parte de los líderes del Confraternidad. Uno de los autores de El Guanacaste insistía que los hombres de Guanacaste debían apoyar la Alianza Democrática con el fin de "honrar la sangre chorotega para salvar la dignidad de los guanacastecos." 57

La Alianza Democrática estaba compuesto por grupos políticos que sabían que no podían ganar las elecciones, pero que podían utilizar la oportunidad de la campaña para educar y concientizar a la gente políticamente. ${ }^{58}$ La propaganda electoral de la Alianza llamaba a Calderón Hitler de Costa Rica y denunciaba los ataques del gobierno autoritario contra

$54 \quad$ "Al definirse la Confraternidad por la candidatura de don Ricardo demostró con su actitud que no solamente se interesa por los problemas del Guanacaste, sino también por los problemas nacionales," y "La salud del Doctor Vargas," El Guanacaste, 18/6/1939, 1. "El regreso del Dr. Vargas, Jefe de la Confraternidad," El Guanacaste, 25/6/1939, 1. El secretario del Partido Oscar Ruiz Centeno informó que Vargas había recibido un monto considerable de correspondencia y le resultaba imposible responder inmediatamente. "A los amigos y simpatizantes del Doctor Francisco Vargas Vargas,” ibid., 2. "Presidida por el Dr. Vargas, en una nueva convención política la Confraternidad Guanacasteca definirá hoy su nuevo rumbo," El Guanacaste, 23/7/1939, 1.

56 "Para que no se engañe más al Pueblo: jugoso y vibrante Manifiesto Político del Dr. Fco. Vargas al país y a la Confraternidad," El Guanacaste, 6/8/1939, 1. "La lucha de abnegación y sacrificio iniciada por Alianza Democrática Nacional recuerda la pasada campaña de Confraternidad Guanacasteca,” El Guanacaste, 27/8/1939, 1. Ver también, Gilberto Canales Rivas, "Las hojas secas varían de dirección con solo un soplo,” El Guanacaste, 27/8/1939, 2 y 4.

57

Gilberto Canales Rivas, ibid., 2. 
el doctor Vargas y el candidato comunista Manuel Mora. ${ }^{59}$ El discurso del Partido Confraternidad Guanacasteca en esta segunda campaña electoral se parecía muy poco al regionalismo fervoroso de la campaña dos años antes. Las demandas del partido en este momento no eran particularmente regionalistas, sino que tenían que ver con problemas de justicia social, derechos y democracia en general. ${ }^{60}$ Cuando los seguidores republicanos de Ricardo Jiménez abandonaron la campaña electoral en diciembre, una convención más fue necesaria, esta vez, en el dormitorio al lado de la cama del convalesciente doctor Vargas. ${ }^{61}$ Un mes después, la Alianza se rompió. Los comunistas reprochaban a los confraternos por ayudar indirectamente al partido calderonista, mientras que los confraternos argumentaban que ellos representaban la opción para los que no querían afiliarse con el calderonimos ni con el comunismo. ${ }^{62}$ El Partido Confraternidad Guanacasteca entonces fue más allá de sus límites territoriales y escogió candidatos al Congreso en varias provincias. Como consecuencia, el discurso regionalista disminuyó su importancia en el Partido Confraternidad Guanacasteca. El Guanacaste denunciaba los problemas sociales del país entero y, por el momento, dejó al lado los reclamos y demandas regionalistas. ${ }^{63}$

Después de las elecciones de 1940, la nueva administración comenzó a materializar políticas reformistas y una legislación social progresista, y luego se alió con la Iglesia Católica y el

59 “Hechos son amores y no buenas razones,” El Guanacaste, 29/10/1939, 1 y 4. “El Dr. Vargas y Manuel Mora, blanco de la furia gobiernista,” El Guanacaste, 19/11/1939, 1.

60 "Frente a la imposición oficial, se levanta el pueblo dispuesto a defender SUS DERECHOS. Dos partidos encabezarán a los costarricenses que quieren defender sus derechos Confraternidad Gteca y Bloque Obreros y Campesinos.” El Guanacaste, 3/12/1939, 1. El periódico publicó el manifiesto del comité central del Bloque de Obreros y Campesinos.

61 "Recordamos que la Confraternidad Guanacasteca es en este momento, uno de los vértices del triángulo que, con el nombre de Alianza Democrática Nacional, ataja a manera de dique las tendencias totalitarias, que amenazan cegar y destruir las instituciones de verdadera democracia que han regido a nuestra patria.” El Guanacaste, 18/12/1939, 1 y 3.

62 “...cumplimos con nuestro deber ciudadano, además de que así damos, a esos miles de costarricenses inconformes, la oportunidad de no volar sus votos o quedarse sin votar.” Rafael Armando Rodríguez, "En nuestras filas no hay calderonismo disimulado... Mal pueden los comunistas llamarnos tureca de ese partido." El Guanacaste, 21/1/1940, 1.

63 El movimiento regionalista, políticamente debilitado, renacería después de 1950, pero en una forma más cultural que abiertamente político-electoral. 
Partido Comunista (especialmente entre los años 1942 y 1943). Esta alianza inusual abrió un período especial en Costa Rica y creo las bases para el camino hacia un estado benefactor y, al mismo tiempo, socavó las posibilidades del Partido Confraternidad Guanacasteca de ganar apoyo como defensor de la justicia social y el desarrollo regional. A finales de los años 1930, Vargas y Confraternidad ofrecían a los guanacastecos un populismo mesiánico que encendía las imaginaciones y generaba expectativas tanto en los sectores medios y las elites marginales como en las masas de empobrecidos trabajadores rurales. Si el partido hubiese llegado algún día al poder, estos sectores habrían enfrentado varios dilemas de ejecución de políticas: la retórica conciliadora de la "fraternidad regional” habría sido difícil de materializar en las condiciones de intereses conflictivos dentro de la coalición, para no mencionar los efectos complicados provenientes de afuera. Pero mientras el doctor Vargas convalecía, otro médicopolítico mesiánico, el doctor Calderón, logró realizar maniobras estratégicas necesarias para conseguir que el mismo cambio de rumbo populista en el estado nacional y de paso robar a los confraternos su recurso retórico. Cabe anotar que, por el carisma particular de Calderón, él y sus aliados pudieron mantener abierta la ventana de oportunidad de su coalición populista solo por ocho años, después de los cuales la guerra civil los echó del poder y un tercer movimiento, liderado por reformistas de sectores medios, les arrebató su lugar. En su ofensiva populista de finales de la década de 1930, los activistas e intelectuales de clase media de El Guanacaste parecieran haber sido totalmente típicos por su clase social y por la cohorte en toda la nación-muy contrariamente a su retórica del excepcionalismo guanacasteco. Vista desde esta óptica, una vez más, los imaginarios políticos de la región y la nación, en vez de oponerse, se refuerzan mútuamente.

\section{Conclusión}

En Guanacaste, la crisis del treinta llevó a un conflicto abierto sobre la tierra y a tensiones en las haciendas por las condiciones de trabajo en deterioro progresivo. A mediados de los años treinta, una intensa organización regionalista (incluyendo la sociedad La Casa de Guanacaste y el periódico El Guanacaste) surgió entre los activistas e intelectuales guanacastecos, quienes realizaron un esfuerzo extraordinario para sistematizar y fortalecer las bases ideológicas y la organización política de su movimiento. La agitación llegó a su punto supremo en 1937, cuando se creó el Partido Confraternidad Guanacasteca y surgió el movimiento político de masas en Guanacaste. 
Coincidiendo con la agudización de los conflictos sociales en la provincia, debido a la crisis, los líderes del movimiento regionalista formularon un discurso de lucha ante el Estado nacional, basado en la conciliación de clases y el olvido de las diferencias sociales dentro de la provincia. La confusión ideológica del movimiento regionalista abarcó también al Partido Confraternidad Guanacasteca, cuyo caudillo ofrecía la redención tanto para los trabajadores como para los patronos en la provincia en un momento histórico en que los trabajadores del campo trababan de defenderse ante el aumento de los niveles de explotación en las haciendas. El movimiento regionalista guanacasteco de los años 1930 era ideológicamente ambiguo e internamente contradictorio, ya que múltiples intereses de clase encontraron importantes espacios de expresión en el periódico y el Partido. El movimiento político que pretendía representar a "todos" los guanacstecos, tanto elites como subalternos, llegó a su fin cuando las masas subalternas en Costa Rica (incluyendo la resonante mayoría de guanacastecos pobres) prefirieron identificarse con la alianza política de socialcristianos y comunistas. El Partido tuvo éxito en su primera experiencia electoral, pero decayó de manera decisiva en años posteriores, cuando el contexto nacional llegó a definirse por la coalición populista de socialcristianos y comunistas.

En conclusión, la caída rápida del Confraternidad Guanacasteca se debe principalmente a dos factores. Primero, el partido se construyó alrededor de una figura de caudillo insustituible, y no existió un esfuerzo sistemático de formación de cuadros entre los militantes del partido. Por tanto, cuando el lider se incapacitó por enfermedad, no hubo otra persona con el poder convocatorio del doctor Vargas, cuya personalidad opacó a cualquier otra posible figura. Tampoco el doctor Vargas insistió en la preparación de líderes para reforzar el trabajo de la dirección del partido, sino que prefirió disfrutar su papel de salvador de la provincia mientras era posible. Segundo, tanto el ideario mesiánico de Vargas como su discurso populista sobre la reconciliación de clases y la búsqueda de soluciones a los problemas de Guanacaste en armonía social perdieron en la competencia ideológica al socialcristianismo del doctor Calderón Guardia, quien logró aglutinar una coalición populista en el nivel nacional a partir de la campaña electoral de 1938. La posible base social para los futuros triunfos electorales del doctor Vargas Vargas se vio debilitado de manera fatal todavía más a partir de 1943, cuando el gobierno de Calderón Guardia formó una alianza política con el partido comunista y la iglesia católica. 